\title{
Migração para áreas rurais do estado de Goiás: uma análise baseada nos dados do Censo Demográfico de 2010*
}

Migration to rural areas of the state of Goiás: an analysis based on data from the 2010 Demographic Census

\section{La migration aux zones rurales de l'Etat de Goiás: une analyse depuis les données du Recensement Démographique de 2010}

La migración para áreas rurales del estado Goiás: un análisis basado em los datos del Censo

Demográfico de 2010

\author{
Priscila Casari** \\ (pricasari@gmail.com) \\ Lilian Lopes Ribeiro*** \\ (liadiniz-21@hotmail.com) \\ João Pedro Tavares Damasceno** \\ (tavaresgyn@gmail.com)
}

Recebido em 16/09/2013; revisado e aprovado em 28/11/2013; aceito em 03/02/2014

\begin{abstract}
Resumo: O objetivo deste artigo é analisar a migração para as áreas rurais de Goiás, relacionando-a ao desenvolvimento do estado e à seleção de migrantes. São utilizados dados do Censo Demográfico de 2010 e apresentadas estatísticas descritivas sobre o volume de migrantes, sua origem e características socioeconômicas. Os resultados mostram que há expressivas diferenças socioeconômicas entre os migrantes oriundos de cada região, sendo que os migrantes vindos das regiões Norte e Nordeste são, em média, negativamente selecionados.

Palavras-chave: Migração. Desenvolvimento. Goiás.

Abstract: The objective of this paper is to analyze the migration to rural areas of Goiás, relating to the development of the state and the selection of migrants. It is used data from Census 2010 and presented descriptive statistics on the volume of migrants, their origin and socioeconomic characteristics. The results show that there are significant socioeconomic differences among migrants from each region and that migrants from the North and Northeast are,
\end{abstract} on average, negatively selected.

Key words: Migration. Development. Goiás.

Résumé: L'objectif de cet article est d'analyser la migration aux zones rurales de Goiás en relation au développement de l'Etat et à la sélection des migrants. Ont été utilisées les données du Recensement Démographique de 2010 et des statistiques descriptives sont présentées sur le volume de migrants, leur origine et caractéristiques socio-économiques. Les résultats montrent qu'il existe des différences socio-économiques expressifs entre les migrants originaires de chaque région et que les migrants originaires des régions Nord et Nor-est sont, en moyenne, négativement sélectionnés.

Mots-clés: Migration. Développement. Goiás.

Resumen: Este artículo tiene como objetivo analizar la migración para áreas rurales de Goiás y su relación con el desarrollo del Estado y con la selección de migrantes. Son utilizados datos del Censo Demográfico de 2010 y presentadas estadísticas descriptivas sobre el volumen de migrantes, su origen y características socioeconómicas. Los resultados muestran que existen expresivas diferencias socioeconómicas entre los migrantes de distintas regiones, siendo que los migrantes originados de las regiones Norte y Nordeste del país son, en media, negativamente seleccionados.

Palabras clave: Migración. Desarrollo. Goiás.

\section{Introdução}

Segundo Oliveira et al. (2011), a região Centro-Oeste e, especificamente, o estado de Goiás, têm recebido um número expressivo de migrantes. Entretanto muito pouco de sabe sobre esses migrantes. De forma geral, os estudos sobre a migração para Goiás têm um enfoque histórico e analisam dados até o ano 2000. Nesses estudos, fica clara a relação entre o desenvolvimento do estado de Goiás e a atração de migrantes.

\footnotetext{
* Este artigo é resultado do projeto de pesquisa “Migração e seleção: evidências para o desenvolvimento do estado de Goiás", financiado pela Fundação de Amparo à Pesquisa do Estado de Goiás.

** Universidade Federal de Goiás (UFG), Goiânia, Goiás, Brasil.

*** Universidade Federal do Ceará, Sobral, CE, Brasil.
} 
No entanto a migração em si também tem efeito sobre o desenvolvimento regional. Segundo Borjas (1987) e Chiswick (1999), os migrantes podem ser positivamente ou negativamente selecionados, dependendo de seu capital humano. Os migrantes positivamente selecionados podem ter efeitos positivos sobre o desenvolvimento da região, enquanto migrantes negativamente selecionados podem gerar efeitos negativos, especialmente, sobre o mercado de trabalho.

Dessa forma, as pesquisas sobre as características dos migrantes e sua inserção no mercado de trabalho são importantes para a elaboração de políticas voltadas ao desenvolvimento regional. Além disso, considera-se que há diferenças expressivas entre o mercado de trabalho rural e urbano que tornam mais apropriada a separação das áreas rurais e urbanas para a análise da migração.

A partir desse contexto, o objetivo geral deste artigo é analisar a migração para as áreas rurais do estado de Goiás, sendo que, especificamente, procura-se descrever a evolução do volume de migrantes ao longo do tempo relacionando a migração ao desenvolvimento do estado; identificar o estado de origem dos indivíduos que migraram na última década; caracterizar os migrantes recentes ${ }^{1}$ de acordo com sua região de origem, evidenciando aspectos relacionados à seleção destes.

Para atingir esses objetivos, apresentase a revisão da literatura que relaciona a migração ao desenvolvimento, e são utilizados dados do Censo Demográfico de 2010 para apresentar estatísticas descritivas sobre o volume de migrantes em Goiás, sua origem e características socioeconômicas.

Além desta introdução, o artigo está dividido em mais cinco seções: a segunda seção apresenta uma revisão da literatura sobre migração para Goiás; a terceira seção discute aspectos teóricos sobre a relação entre migração e seleção; a quarta seção apresenta a metodologia; na quinta seção estão os resultados; e, na sexta seção, estão as considerações finais.

\footnotetext{
${ }^{1}$ Por migrantes recentes, entendem-se aquelas pessoas que migraram para as áreas rurais do Estado de Goiás na última década.
}

\section{Revisão da literatura sobre a migração para o estado de Goiás}

Nesta seção, procura-se apresentar a literatura recente sobre a migração para o estado de Goiás e a sua relação com o desenvolvimento regional. Percebe-se que há um consenso entre os autores que pesquisam o tema migração para o Estado de Goiás de que as principais mudanças econômico-populacionais no estado começaram a acontecer com o projeto de "Marcha para o Oeste", a partir do Estado Novo, e, em seguida, com o "Plano de Metas", no governo de Juscelino Kubitscheck.

Com a "Marcha para o Oeste", Goiás passou a ser fornecedor de gêneros alimentícios e matérias-primas e também um absorvedor de excedentes populacionais de outras regiões do país. Assim, a "Marcha para o Oeste" é, historicamente, para Cunha (2002) um marco no processo de migração para o Estado de Goiás.

Cunha (2002) apresenta um levantamento histórico sobre a migração para o Centro-Oeste brasileiro, no período de 1986 a 1996. Segundo o autor, a marcha para o Oeste é apresentada como um movimento importante na década de 1970, todavia o autor argumenta que, na década de 1980, houve uma diminuição dessa migração devido ao "esgotamento ou, simplesmente, a redução dos recursos destinados ao incentivo à colonização da agricultura, as mudanças de cultivo e modificações na estrutura fundiária" (CUNHA, 2002, p. 89). O autor ainda argumenta que essa redução permaneceu nos anos de 1990.

Para seu trabalho, Cunha (2002) utiliza dados censitários de 1991 e da contagem de 1996, buscando analisar as "características dos migrantes em termos demográficos, de inserção produtiva e de aspectos socioeconômicos, como educação e renda" (CUNHA, 2002, p. 90). Um dado importante apresentado pelo autor é que, nos anos 1970 e 1980, a migração enfrentou duas realidades: "a primeira ligada ao processo de ocupação e expansão das fronteiras agrícolas e, a segunda, relativa ao crescimento de aglomerações urbanas, em geral, liberadas pelas capitais dos Estados" (CUNHA, 2002, p. 96).

Ao comparar a migração para o Estado de Goiás e para o Distrito Federal, Cunha (2002) afirma que a migração para o Distrito 
Federal não foi influenciada pela fronteira agrícola, diferente de Goiás, que, por ter sido influenciada, deixou de ser um polo de atração nos anos 1980 e 1990.

Ao tratar especificamente do Estado de Goiás, Cunha (2002, p. 107) observa que, no período de 1986/1996,

[...] aumentou, ainda que timidamente, os seus volumes e taxas de imigração no período e viu seu saldo migratório elevar-se devido à tendência decrescente da emigração, fato que, em grande medida explica a manutenção de seu crescimento demográfico em níveis altos para os padrões brasileiros e até mesmo regionais.

Além disso, o autor apresenta a relação do Estado com o Distrito Federal com a chegada de nordestinos (principalmente os baianos) e que os mineiros são migrantes para o estado de Goiás nas décadas de 1980 e 1990.

Todavia o autor não faz distinção entre a zona urbana e a zona rural, o que deixa uma lacuna para que se possam verificar as relações entre a migração e o desenvolvimento rural do Estado de Goiás. São poucos os trabalhos que analisam a migração para as áreas rurais, podem ser citadas, além de Cunha (2002), algumas pesquisas que foram realizadas com o objetivo de investigar as características dos migrantes que se destinaram ao Estado de Goiás, como: Bezerra e Cleps Júnior (2004), Pádua (2008), Amaral (2009) e Amaral et al. (2007).

Bezerra e Cleps Júnior (2004) tratam do desenvolvimento agrícola e das transformações no espaço agrário do estado de Goiás. Segundo esses autores, nos anos 1950 e 1960, "a fronteira agrícola constitui uma "válvula de escape" para os problemas populacionais gerados pelo processo de urbanização" (BEZERRA; CLEPS JUNIOR, 2004, p. 35). Assim, os autores argumentam que o estado de Minas Gerais foi o principal responsável pela migração para Goiás nas áreas de fronteiras, seguidos pelos estados da região nordeste, como Maranhão e Bahia. Segundo esses autores:

A nova fronteira agrícola esteve assenta$\mathrm{da}$, durante um período, em projetos de colonização privados e estatais, que entraram em crise, tanto por falta de interesse político como por falta de planejamento e investimentos. Os agricultores que viviam nos assentamentos foram gradativamente engolidos pelos latifundiários, expondo a ineficiência desses projetos. (BEZERRA; CLEPS JUNIOR, 2004, p. 35).
Pode-se observar na tabela abaixo, elaborada por Bezerra e Cleps Júnior (2004), os principais estados de origem dos migrantes para Goiás em 1940 e 1950:

Tabela 1 - Distribuição percentual dos migrantes conforme seu estado de origem

\begin{tabular}{lrr}
\hline \multicolumn{1}{r}{ Estado } & \multicolumn{1}{r}{$\mathbf{1 9 4 0}$} & $\mathbf{1 9 5 0}$ \\
\hline Minas Gerais & 44,77 & 53,32 \\
Maranhão & 21,3 & 16,72 \\
Bahia & 20,66 & 15,74 \\
São Paulo & 4,63 & 5,41 \\
Piauí & 4,66 & 4,31 \\
Outros & 3,98 & 4,5 \\
\hline
\end{tabular}

Outro autor que vem desenvolvendo importantes pesquisas sobre migração no Brasil e que tem muitos de seus trabalhos sobre a região Centro-Oeste é Ernesto Friedrich de Lima Amaral. Amaral et al. (2007) contribui com a literatura sobre as mudanças demográficas nos países em desenvolvimento e no estudo sobre o tamanho e a estrutura do mercado de trabalho e a educação da mão de obra no Brasil. Seu trabalho conclui que a oferta de mão de obra está crescendo rapidamente e em diferentes áreas do mercado de trabalho.

Em outra pesquisa, Amaral (2009) apresenta as características dos migrantes do Estado de Goiás e Distrito Federal em relação a sua região de origem e de destino. Seu trabalho teve como dados os Censos de 1980, 1991 e 2000 do Instituto Brasileiro de Geografia e Estatística (IBGE) e suas preocupações se pautaram na migração para os centros urbanos - atenção inversa do que se propõe o presente trabalho, mas que ajuda a caracterizar o fluxo migratório que se deu no Estado ao longo das últimas décadas.

Segundo Amaral (2009), no período de 1986 a 1990, a maioria dos migrantes com destino à Goiânia tinha como origem o próprio estado de Goiás (34,45\%); em seguida, vieram migrantes da região Norte $(27,40 \%)$; Nordeste (16,45\%); Sudeste (13,29\%); Distrito Federal (8,36\%); Mato Grosso e Mato Grosso do Sul $(4,57 \%)$ e Sul (1,53\%).

Em relação à zona rural, Pádua (2008) mostra que, nas décadas de 1940 e 1950, Goiás apresentou alto índice de ocupação da zona rural, todavia, a partir de 1960, a agricultura deixou de ser uma atividade atrativa para migrantes e perdeu esse posto para os 
setores industriais e de serviços no estado de Goiás, que aumentaram sua participação na economia.

Pádua (2008) observa que a população rural de Goiás cresceu de 684.304, em 1940, para 1.701.569, em 1970, quando atingiu seu pico. A partir da década de 1980, a população rural vem decrescendo, sendo 606.583, em 2000. Segundo a autora, o motivo é "um processo de descolamento da população rural para as cidades, por causa da modernização agrícola do Estado que provocou o êxodo rural, e em busca de melhorias sociais que incrementam o fluxo migratório para a região" (PÁDUA, 2008, p. 31).

A autora analisa o crescimento demográfico de Goiás relacionando-o com o crescimento da economia no Estado. Em seu trabalho, verifica que o Produto Interno Bruto (PIB) da região tem crescido a taxas superiores à média nacional nas últimas décadas e que a migração populacional continua acelerada no território goiano, embora a expansão econômica não tenha sido suficiente à expansão da população economicamente ativa regional (PÂDUA, 2008, p. 7).

Mais recentemente, segundo Segplan (s.d.), entre os anos de 2002 e 2009, o PIB de Goiás passou de pouco mais de $\mathrm{R} \$ 37$ milhões para quase R $\$ 89$ milhões. Esse crescimento foi acima da média nacional e levou ao aumento da participação no PIB nacional de 2,53\% para $2,64 \%$. Um reflexo desse crescimento é a atração de migrantes.

Dados de Oliveira et al. (2011) apontam que, entre os anos de 2004 e 2009, a região Centro Oeste recebeu 418 mil imigrantes, enquanto 281 mil emigraram. Um saldo migratório de 137 mil pessoas que consolida os estados do Centro Oeste brasileiro como polo de atração de população das demais regiões brasileiras. Em relação a Goiás, segundo Oliveira et al. (2011), o estado se caracteriza por receber grandes quantidades de migrantes oriundos de diversos estados, especialmente, Distrito Federal, Bahia, Minas Gerais, São Paulo, Tocantins e Maranhão.

Na próxima seção, são discutidos possíveis efeitos da migração sobre o desenvolvimento e a necessidade de políticas públicas.

\section{Aspectos teóricos sobre a relação entre migração e seleção}

Os migrantes positivamente selecionados, na concepção de Borjas (1987) e Chiswick (1999), apresentam maior nível de capital humano e têm um impacto forte na promoção do desenvolvimento da região receptora. Por outro lado, os migrantes negativamente selecionados têm menores níveis de capital humano e, portanto, demandam mais políticas públicas, principalmente, voltadas à educação e ao trabalho.

O primeiro autor a teorizar sobre seleção positiva em estudos de migração foi Borjas (1987). O objetivo de sua pesquisa, que teve sua hipótese comprovada, era de verificar se os imigrantes dos Estados Unidos formavam um grupo positivamente selecionado, ou seja, em média mais dotados de certos atributos cognitivos como: ambição, maior capacidade de adaptação, agressividade e empreendedorismo.

Anos depois, Borjas (1987) constatou também que os imigrantes oriundos de regiões ricas possuem salários mais altos por serem "dotados", além de maiores atributos cognitivos, também de um maior nível de capital humano. E que esses imigrantes com tais atributos e alta formação escolar têm um impacto mais forte sobre o desenvolvimento da região receptora de tais imigrantes. Chiswick (1999) também comprovou que os imigrantes ganham mais que os nativos e justificou a superioridade nos salários como sendo fruto de seus atributos cognitivos. Desde o trabalho de Borjas (1987), inúmeras pesquisas sobre migração e seleção têm sido realizadas no mundo, algumas delas no Brasil. Apesar da vasta literatura internacional sobre o tema, no Brasil os estudos sobre migração e seleção são relativamente recentes. Destacam-se os trabalhos de Ramos e Araújo (1999); Santos Júnior (2002); Ferreira et al. (2003); Santos e Ferreira (2007) e Ribeiro e Correa (2009). Ferreira et al. (2003) e Santos e Ferreira (2007), com base em dados da PNAD de 2003, perceberam que no Brasil os migrantes são mais bem remunerados que os não-migrantes e também mais que seus conterrâneos que não migram.

Santos e Ferreira (2007), usando dados da PNAD de 2002, mostram que 19,94\% da população brasileira constituíam-se de mi- 
grantes naquele ano. De acordo com esses autores, esse percentual foi ainda maior no ano seguinte, atingindo $38,28 \%$, utilizando-se a mesma base de dados. Os autores reforçam a assertiva de que os estados da região Centro-Oeste estão entre aqueles que mais recebem migrantes no País.

Diante das assertivas apresentadas e a escassez de pesquisas que tratem da migração para as áreas rurais do Estado de Goiás, este artigo visa contribuir com a literatura analisando a evolução da migração e trazendo evidências sobre a seleção e a necessidade de políticas públicas em Goiás.

\section{Metodologia}

Para atingir o objetivo de analisar a migração para as áreas rurais do estado de Goiás, são utilizados dados do Censo Demográfico de 2010 do IBGE. Essa base de dados foi escolhida, pois representa a totalidade da população brasileira, incluindo as áreas rurais, e traz informações detalhadas sobre migração.

No ano de 2010, segundo dados do Censo, a amostra da população rural do estado de Goiás foi de 114.751 pessoas, o que representa 582.787 residentes na zona rural. Neste artigo, a população estudada é formada pelos migrantes de outros estados residentes em áreas rurais de Goiás, sendo que a amostra é de 23.350 pessoas, que representa um total de 118.587 migrantes, indicando que 20,35\% da população rural é migrante.

A partir desta amostra, calcula-se, inicialmente, o número de migrantes de acordo com a década de migração. Dessa forma, é apresentada a evolução da migração ao longo do tempo. É importante ressaltar que os números de migrantes calculados não refletem o total da migração para as áreas rurais de Goiás, mas sim as décadas em os atuais residentes da zona rural migraram para Goiás ${ }^{2}$.

Em seguida, procura-se analisar mais detalhadamente a origem e as características socioeconômicas dos migrantes recentes, ou seja, daqueles que migraram para áreas rurais de Goiás de 2001 a 2010. Para tanto, descreve-se a distribuição dos migrantes por

2 Estão excluídos do número calculado de migrantes aqueles que migraram para áreas rurais de Goiás em um dado ano passado, porém não mais residem nessas áreas. estado de origem e também algumas características dos migrantes de acordo com sua região de origem (Norte, Nordeste, Sudeste, Sul e Centro-Oeste). Essas características são pessoais e relacionadas ao mercado de trabalho, quais sejam:

- sexo masculino: percentual de migrantes do sexo masculino;

- idade: idade média em anos;

- cores branca e amarela: percentual de migrantes das cores branca ou amarela;

- escolaridade: percentual de migrantes em cada nível de escolaridade, considerandose ensino fundamental incompleto, ensino médio incompleto, ensino superior incompleto ou ensino superior completo ou mais;

- População Economicamente Ativa (PEA): percentual de migrantes que participam da PEA, sendo que a PEA é formada pelos indivíduos com dez anos ou mais de idade que estejam trabalhando ou procurando emprego;

- taxa de desemprego: percentual de migrantes desempregados (migrantes desempregados / migrantes que fazem parte da PEA);

- tipo de emprego: percentual de migrantes em cada tipo de emprego, considerandose emprego formal, emprego informal, trabalhador por conta própria ou empregador; e

- rendimento total: rendimento mensal que inclui todas as fontes de renda, em R\$.

Assim, procura-se relacionar a migração ao desenvolvimento, além de evidenciar aspectos relacionados à seleção de migrantes.

\section{Resultados}

Nesta seção, são apresentados os resultados sobre a evolução do volume de migrantes, a origem dos indivíduos que migraram para as áreas rurais de Goiás na última década e também sobre as características dos migrantes recentes de acordo com sua região de origem.

A seguir, a figura 1 mostra o número de migrantes, da amostra do Censo 2010, residentes em áreas rurais de Goiás, por década de migração. 


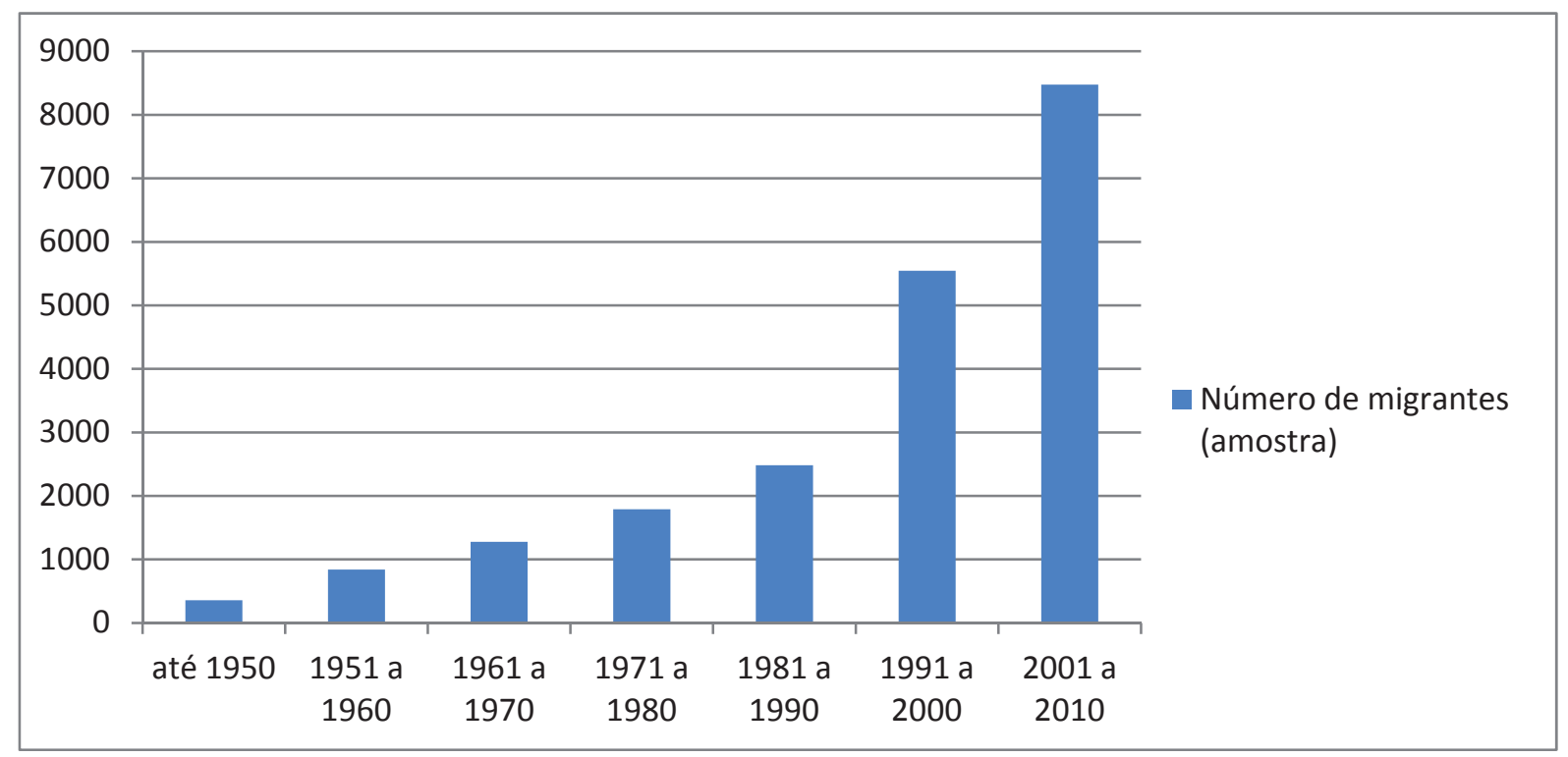

Figura 1 - Amostra do número de migrantes, residentes em áreas rurais de Goiás, por década de migração

Fonte: elaborado pelos autores com base nos dados do Censo 2010.

A partir dos dados da figura 1, é possível analisar a evolução da migração para a zona rural de Goiás. Verifica-se que, entre os atuais migrantes residentes em áreas rurais do estado, cerca de $1,71 \%$ migrou para Goiás até o ano de 1950; 4,04\% migraram entre 1951 e $1960 ; 6,15 \%$, de 1961 a $1970 ; 8,62 \%$, de 1971 a 1980; 11,96\%, de 1981 a 1990; 26,70\%, de 1991 a 2000; e 40,81\% migraram durante a última década, de 2001 a 2010. Considerando todos os migrantes da amostra, o tempo médio de residência no estado de Goiás é de 15,32 anos.

Com isso, pode-se concluir que, entre os atuais migrantes residentes em áreas rurais de Goiás, há uma elevada concentração, cerca de $67,51 \%$ destes, que se mudaram para o estado após 1991. Dessa forma, mesmo havendo redução da população rural, causada pela modernização da agropecuária, como evidenciado por Pádua (2008), observa-se que há um importante movimento migratório para as áreas rurais de Goiás, especialmente, na última década. Esse movimento migratório pode ter sido causado pelo desenvolvimento da agropecuária no estado e ainda pelas taxas de crescimento maiores que a média nacional, como apontado pelo Segplan (s.d.).

A tabela 1 apresenta a distribuição dos migrantes recentes segundo o estado de origem.
Tabela 1 - Distribuição percentual dos migrantes recentes, residentes em áreas rurais de Goiás, segundo o estado de origem.

\begin{tabular}{l|c}
\hline Estado & Percentual \\
\hline Rondônia & 0,38 \\
Acre & 0,05 \\
Amazonas & 0,18 \\
Roraima & 0,08 \\
Pará & 3,16 \\
Amapá & 0,05 \\
Tocantins & 7,02 \\
Maranhão & 4,33 \\
Piauí & 2,83 \\
Ceará & 2,38 \\
Rio Grande do Norte & 1,01 \\
Paraíba & 1,61 \\
Pernambuco & 1,90 \\
Alagoas & 1,02 \\
Sergipe & 0,18 \\
Bahia & 11,23 \\
Minas Gerais & 14,45 \\
Espírito Santo & 0,24 \\
Rio de Janeiro & 0,35 \\
São Paulo & 5,39 \\
Paraná & 1,69 \\
Santa Catarina & 0,62 \\
Rio Grande do Sul & 1,79 \\
Mato Grosso do Sul & 4,19 \\
Mato Grosso & 7,49 \\
Distrito Federal & 26,41 \\
\hline
\end{tabular}

Fonte: elaborado pelos autores com base nos dados do Censo (2010) 
Entre as pessoas que migraram para a zona rural goiana de 2001 a 2010, observa-se que o maior percentual de migrantes tem como origem o Distrito Federal. Uma possível explicação é a pouca atividade agrícola no Distrito Federal e o crescimento das áreas urbanas que podem estar causando a migração para Goiás, que é seu estado vizinho.

Em seguida, observam-se os maiores percentuais de migrantes são oriundos de Minas Gerais e Bahia. Esses estados, juntamente com o Distrito Federal, têm sido a origem de uma parcela significativa dos migrantes há várias décadas, assim como constata Cunha (2002) Bezerra e Cleps Júnior (2004).

Por outro lado, segundo Amaral (2009), no período de 1986 a 1990, a maioria dos migrantes com destino à cidade de Goiânia tinha como origem o próprio estado de Goiás, seguidos pelos migrantes oriundos da região Norte $(27,40 \%)$. No caso da migração para as áreas rurais, verifica-se que a região Norte não é tão representativa, à exceção do estado do Tocantins. Dessa forma, embora não seja o propósito deste artigo comparar a migração rural e urbana, acredita-se que haja diferença significativa entre a migração para a zona rural do estado e para a capital de Goiás.
Analisando a origem dos migrantes recentes por região, contata-se que:

- $10,92 \%$ dos migrantes têm a região Norte como origem e, entre estes, o estado que mais provê migrantes é o Tocantins;

- a região Nordeste é responsável por $26,49 \%$ dos migrantes, destacando-se os estados da Bahia e Maranhão;

- da região Sudeste, vieram $20,43 \%$ dos migrantes, sendo 14,45\% de Minas Gerais e 5,39\% de São Paulo;

- a região Sul é a origem da menor parcela de migrantes, $4,1 \%$;

- e, da própria região Centro-Oeste, vieram 38,09\%, destacando-se o Distrito Federal.

A partir desse resultado, pode-se concluir que os migrantes residentes em áreas rurais goianas são oriundos das diversas regiões do país. Entretanto deve-se considerar que há diferenças significativas no nível de desenvolvimento dessas regiões, que podem se refletir em diferenças na escolaridade, renda per capita e no mercado de trabalho em geral.

A tabela 2 explora essas diferenças, evidenciando algumas características socioeconômicas dos migrantes de acordo com sua região de origem.

Tabela 2 - Características socioeconômicas dos migrantes recentes, residentes em áreas rurais de Goiás, de acordo com sua região de origem

\begin{tabular}{l|r|c|c|c|c}
\hline \multicolumn{1}{c|}{ Variável } & Norte & Nordeste & Sudeste & \multicolumn{1}{c|}{ Sul } & Centro-Oeste \\
\hline sexo masculino (em \%) & 52,71 & 55,06 & 55,22 & 51,87 & 51,41 \\
idade (em anos) & 27,19 & 27,10 & 32,26 & 31,48 & 26,70 \\
$\begin{array}{l}\text { cores branca e amarela (em \%) } \\
\text { escolaridade (em \%): }\end{array}$ & 24,90 & 23,30 & 42,51 & 70,53 & 33,78 \\
$\quad$ ensino fundamental incompleto & 74,88 & 77,43 & 67,94 & 57,31 & 70,87 \\
$\quad$ ensino médio incompleto & 15,74 & 15,56 & 15,91 & 14,67 & 14,93 \\
$\quad$ ensino superior incompleto & 07,57 & 06,03 & 11,36 & 23,15 & 12,03 \\
$\quad$ ensino superior & 01,54 & 00,50 & 04,43 & 04,71 & 01,79 \\
PEA (em \%) & 55,00 & 63,13 & 58,85 & 71,34 & 56,34 \\
taxa de desemprego (em \%) & 06,22 & 06,26 & 02,19 & 03,84 & 08,45 \\
tipos de emprego (em \%): & & & & & \\
$\quad$ emprego formal & 48,99 & 51,21 & 53,36 & 66,12 & 48,21 \\
$\quad$ emprego informal & 31,04 & 37,39 & 27,62 & 13,32 & 30,46 \\
$\quad$ conta própria & 19,96 & 10,90 & 18,45 & 19,34 & 20,60 \\
$\quad$ empregador & 00,00 & 00,50 & 00,58 & 01,23 & 00,73 \\
rendimento total (em R\$) & 509,28 & 426,51 & 719,19 & 963,80 & 604,19 \\
\hline
\end{tabular}

Fonte: elaborado pelos autores com base nos dados do Censo (2010) 
Comparando-se os migrantes por região, verifica-se que as maiores proporções de homens são oriundas das regiões Sudeste e Nordeste, embora, em todas as regiões, a maioria dos migrantes seja do sexo masculino. Acredita-se que a maior proporção de homens se deva ao trabalho agropecuário nas áreas rurais, que tradicionalmente emprega mais homens que mulheres.

Em relação à idade, percebe-se que os migrantes das regiões Sudeste e Sul são, em média, pelo menos quatro anos mais velhos que os migrantes oriundos de outras regiões. Essa diferença de idade pode refletir maior experiência no mercado de trabalho migrantes vindos do Sudeste e do Sul do país.

A cor dos migrantes mostra-se bastante diferente dependendo da origem deles, enquanto entre os migrantes das regiões Norte e Nordeste, a proporção de brancos e amarelos é menor que $1 / 4$, quando a origem é a região Sul, essa proporção chega a $70 \%$. Essas proporções de brancos e amarelos, em relação aos pretos, pardos e indígenas, mostram reflexos da colonização do país e ainda que a migração contribua para redução dessas diferenças.

Analisando a escolaridade, observa-se que os migrantes menos escolarizados são oriundos do Nordeste, seguidos pela região Norte, Centro-Oeste, Sudeste e Sul, de onde vêm os migrantes com maiores níveis de escolaridade. A escolaridade, assim como a experiência no mercado de trabalho (que tem como proxy a idade), são indicadores importantes do capital humano do migrante, em cuja seleção impacta diretamente. Na concepção de Borjas (1987) e Chiswick (1999), migrantes com elevado nível de capital humano promovem o desenvolvimento da região receptora, por outro lado, migrantes negativamente selecionados, ou seja, com baixo nível de capital humano, têm maiores dificuldades de inserção no mercado de trabalho e demandam mais políticas públicas.

O impacto da seleção pode ser verificado por meio da inserção do migrante no mercado de trabalho. Observa-se que migrantes oriundos das regiões Sul e Sudeste apresentam menores taxas de desemprego, proporções maiores de emprego formal e menores de emprego informal, além de rendimento total médio superior às demais regiões. No outro extremo, estão os migrantes vindos das regiões Nordeste e Norte, que têm menores rendimentos, maiores proporções de emprego informal e maiores taxas de desemprego.

De forma geral, pode-se concluir que os migrantes residentes em áreas rurais de Goiás oriundos da própria região Centro-Oeste estão em situação intermediária aos demais migrantes. Acredita-se ainda que, na zona rural goiana, os migrantes das regiões Sudeste e Sul, em média, sejam positivamente selecionados, enquanto aqueles que têm Norte e Nordeste como origem sejam negativamente selecionados.

\section{Considerações finais}

O objetivo deste artigo foi analisar a migração para as áreas rurais do estado de Goiás e, entre os resultados, pode-se destacar que a maior parte dos migrantes mudou-se para a zona rural de Goiás nas últimas duas décadas, sendo que esses migrantes são oriundos das diversas regiões do país e há expressivas diferenças socioeconômicas entre os migrantes de cada região. Como consequência dessas diferenças, conclui-se que os migrantes das regiões Sudeste e Sul são, em média, positivamente selecionados, e os migrantes das regiões Norte e Nordeste, em média, negativamente selecionados.

A partir desse resultado e considerando que a elevada proporção de migrantes tem como origem as regiões Nordeste e Norte, $37,41 \%$, fica clara a necessidade políticas públicas no estado de Goiás que possam reduzir a desigualdade socioeconômica entre os migrantes.

Essas políticas devem ter como foco os migrantes do Norte e Nordeste do país e visar ao aumento do seu capital humano, por meio da escolarização, haja vista a grande proporção de migrantes com ensino fundamental incompleto. É importante ressaltar que, além da educação básica formal, também se pode incentivar o ensino técnico e cursos profissionalizantes voltados para o trabalho agropecuário, uma vez que esses migrantes são residentes na zona rural.

Além das políticas de escolarização, sugere-se ainda que sejam criadas políticas para garantir o acesso à escola e reduzir a evasão escolar. Podem ser criadas mais escolas nas áreas rurais ou oferecer transporte para as 
escolas nas áreas urbanas, e criar incentivos para a frequência escolar, como a concessão de bolsas para os adultos que frequentam a escola.

Futuras pesquisas podem analisar a migração em outros estados, realizar comparações intrarregionais ou rurais urbanas e estudar a migração temporária.

\section{Referências}

AMARAL, E. F. L. Caracterização de migrantes em Goiás e Distrito Federal: 1980-2000. Teoria e Sociedade, Belo Horizonte, v. 17, n. 2, p. 160-185, jul./dez. 2009.

AMARAL, E. F. L.; HAMMERMESH, D. S.; POTTER, J. E.; RIOS NETO, E. L. G. Demographic change and the structure of wages: a demand-theoretic analysis for Brazil. Cambridge: NBER, 2007. 34 p. (Working Paper 13.533).

BEZERRA, L. M. C.; CLEPS JÚNIOR, J. O desenvolvimento agrícola da região Centro-Oeste e as transformações no espaço agrário do estado de Goiás. Caminhos de Geografia, Uberlândia, v. 2, n. 12, p. 29-49, jun. 2004.

BORJAS, G. J. Self-selection and the earnings of immigrants. The American economic review, Nashville, v. 77, n. 4, p. 531-553, set. 1987.

CHISWICK, B. R. Are immigrants favorably self-selected? The American economic review, Nashville, v. 89, n. 2, p. 181-185, maio 1999.

CUNHA, J. M. P. Migração do Centro-Oeste Brasileiro: as tendências e características do período 1986/96. In: HOGAN, D. J.; CARMO, R. L.; CUNHA, J. M. P.;
BAENINGER, R. Migração e ambiente no Centro-Oeste. Campinas: NEPO, 2002. p. 89-134. Cap. 3.

FERREIRA, P. C. G.; SANTOS JÚNIOR, E. R.; MENEZES FILHO, N. A. Migração, seleção e diferenças regionais de renda no Brasil. Rio de Janeiro: FGV, 2003. (Texto para discussão).

OLIVEIRA, A. T. R.; ERVATTI, L. R.; O’NIELL, M. M. V.C. O panorama dos deslocamentos populacionais no Brasil: PNADs e censos demográficos. In: OLIVEIRA, L. A. P.; OLIVEIRA, A. R. Reflexões sobre os deslocamentos populacionais no Brasil. Rio de Janeiro: IBGE, 2011. Cap. 3.

PÁDUA, A. A. S. Migração, expansão demográfica e desenvolvimento econômico em Goiás. 2008. 113f. Dissertação (Mestrado em Desenvolvimento e Planejamento Territorial) - Universidade Católica de Goiás, Goiânia, 2008.

RAMOS, C. A.; ARAÚJO, H. Fluxos migratórios, desemprego e diferenciais de renda. Rio de Janeiro: IPEA, 1999. 94 p. (Texto para Discussão 656).

RIBEIRO, L. L. CORREA, M. V. Migração e seleção: evidências para o Centro-Oeste brasileiro. Revista Economia Ensaios, Uberlândia, v. 24, n. 1, p. 01-13, jan./jun. 2009.

SANTOS JÚNIOR, E. R. Migração e seleção: o caso do Brasil. 2002. 56 p. Dissertação (Mestrado em Economia) - Fundação Getúlio Vargas, Rio de Janeiro, 2002.

SANTOS, C.; FERREIRA, P. C. Migração e distribuição regional de renda no Brasil. Pesquisa e Planejamento Econômico, Brasília, v. 37, n. 3, dez. 2007.

SEGPLAN. Estado de Goiás: produto interno bruto, taxa de crescimento e participação no PIB do Brasil 2002-2009, [s.d.]. Disponível em: <http:/ / www.seplan. go.gov.br/sepin/pub/pib/2002_go_valores_correntes. htm>. Acesso em: 10 mar. 2013. 